\title{
Factors Associated with Women Unemployment in Ethiopia
}

\author{
Yenew Alemu Mihret \\ Department of Statistics, College of Natural and Computational Science, Injibara University, Injibara, Ethiopia \\ Email address: \\ yenewalemu@gmail.com

\section{To cite this article:} \\ Yenew Alemu Mihret. Factors Associated with Women Unemployment in Ethiopia. International Journal of Theoretical and Applied \\ Mathematics. Vol. 5, No. 5, 2019, pp. 68-73. doi: 10.11648/j.ijtam.20190505.11
}

Received: August 8, 2019; Accepted: November 5, 2019; Published: November 11, 2019

\begin{abstract}
Unemployment is one of the main challenges of the modern era in both the developed and developing countries. Employment of women in economic activities has several beneficial effects for women and their families. Unemployment gives rise to private and social problems in the society such as increased crimes, suicides, poverty, alcoholism and prostitution. High level of unemployment rates can also contribute to the spread of HIV/AIDS in developing countries. In general, unemployment affects household income, health, government revenue and hence GDP and development at large. Studying unemployment therefore helps tackle these problems through some kind of policy actions. The average unemployment rate for women age from $15-49$ was $48.8 \%$. The unemployment rate is still significantly higher among females. Heavy domestic duties, pregnancy and discrimination are some of the reasons for female unemployment. Ethiopian women also earn less than men. Unemployment is more of a problem of women than that of their counterparts. This issue dictates the researcher to consider the determinants and consequences of unemployment of women in Ethiopia. In line with this, the objective of this study is to study the determinants of unemployment of women in the study area. This study used data from Ethiopia Demographic and Health Survey (EDHS), 2016. A Binary Logistic Regression Analysis is used to identify the most important determinant factors which are associated with the occupational status of women in Ethiopia. The result of binary logistic regression model also revealed that place of residence, educational level of woman, currently pregnant, currently breastfeeding, wealth index, age of the respondent at the first birth and marital status had significant effect on women unemployment at $5 \%$ level of significance.
\end{abstract}

Keywords: Unemployment, Women, Binary Logistic Regression, Ethiopia

\section{Background of the Study}

Unemployment is one of the main challenges of the modern era in both the developed and developing countries. Employment of women in economic activities has several beneficial effects for women and their families. Unemployment gives rise to private and social problems in the society such as increased crimes, suicides, poverty, alcoholism and prostitution [1, 2]. High level of unemployment rates can also contribute to the spread of HIV/AIDS in developing countries [3]. In general, unemployment affects household income, health, government revenue and hence GDP and development at large. Studying unemployment therefore helps tackle these problems through some kind of policy actions.

At a global level, female unemployment is higher compared to that of male unemployment. They also suffer from a difference in the quality of employment in comparison to men. Vulnerable employment which comprises contributing family workers and own account workers (as opposed to wage and salaried workers) is more widespread for women than men [4].

Ethiopia is a poor agricultural country with per capita income of USD350 [5]. The general unemployment rate was $20.5 \%$ in 2009 . It was higher for females at $29.9 \%$ compared to males which stood at $12.1 \%$ [5]. A high level of unemployment indicates the failure of a country's economy to use its labour resources effectively. There can be various factors explaining unemployment, such as a low level of general economic activity, recession, inflation, rapid changes in technology, disability, willingness to work and discrimination. In the case of Ethiopia, several factors contribute to the causes of youth unemployment.

Among married women, the percentage currently employed was $32 \%$ in the 2005 EDHS. This increased moderately to $57 \%$ in the 2011 EDHS, and then declined slightly to $48 \%$ in the 2016 EDHS. The percentage of 
employed married women who receive cash earnings increased from $27 \% 2005$ to $36 \%$ in 2011 , and then remained essentially stable at $35 \%$ in 2016 . The percentage of married women not paid for their work declined from $60 \%$ to $30 \%$ between 2005 and 2011 and then increased to $49 \%$ in 2016 .

According to EDHS 2016 survey, unemployed in the 12 months preceding survey for women age 15-19, 20-24, 25$29,30-34,35-39,40-44$ and $45-49$ were $59 \%, 52.7 \%, 46.5 \%$, $43.9 \%, 46.1 \%, 45.1 \%$ and $48.1 \%$, respectively. The average unemployment rate for women age from 15-49 was $48.8 \%$. The unemployment rate is still significantly higher among females. Heavy domestic duties, pregnancy and discrimination are some of the reasons for female unemployment. Ethiopian women also earn less than men. Unemployment is more of a problem of women than that of their counterparts. This issue dictates the researcher to consider the determinants and consequences of unemployment of women in Ethiopia. In line with this, the objective of this study is to study the determinants of unemployment of women in the study area.

\section{Methods}

\subsection{Source of Data}

This study used data from Ethiopia Demographic and Health Survey (EDHS), 2016. The 2016 Ethiopia Demographic and Health Survey (2016 EDHS) was implemented by the Central Statistical Agency (CSA) from January 18, 2016, to June 27, 2016. The funding for the 2016 EDHS was provided by the government of Ethiopia, the United States Agency for International Development (USAID), the government of the Netherlands, the Global Fund, Irish Aid, the World Bank, the United Nations Population Fund (UNFPA), the United Nations Children's Fund (UNICEF), and UN Women. ICF provided technical assistance through The DHS Program, a USAID-funded project providing support and technical assistance in the implementation of population and health surveys in countries worldwide. During the analysis stage, Statistical Package for Social Science (SPSS) version 23, STATA version 14 and Microsoft-Excel are used as tools of analysis. STATA was used in running the binary logistic regression and other analysis while Microsoft-Excel and SPSS were employed to generate numbers and sorting of data respectively. The dependent variable for this study is occupational status of women (no $=1$, yes $=0$ ) and the independent variables are highest education level, Wealth index, place of residence, currently pregnant, currently breastfeeding, currently marital status, ages of the households and age of women at the first birth. Descriptive statistics and bivariate logistic regression analyses have been used in this study.

\subsection{Binary Logistic Regression}

Logistic regression is part of a family of models called the Generalized Linear Model used when the response variable is qualitative or categorical in nature and independent variables can be continuous and/ or categorical. Binomial or binary logistic regression is the form of regression which is used when the dependent variable is dichotomous and the independent variables are of any type [6].

Binary logistic regression techniques resolve inconsistencies associated with dichotomous dependent data and the assumptions of linear regression methods. The independent variables that are used for outcome prediction may be dichotomous, categorical or continuous. Binary logistic regression is commonly used in manufacturing and health related studies. It can be used for any application where binary outcomes can be predicted. Logistic regression is based on the logit transformation of the dependent variable. The logit transformation generates a continuous logarithmic curve from non-continuous data so that a regression model can be developed. The outcome probabilities for each dependent variable value are the basis for the model. The logit transformation is necessary since dichotomous dependent data violates ordinary least squares assumptions. Another issue with dichotomous data is that the error terms are not normally distributed, thus ordinary sum of squares regression and all normality tests are invalid [7].

Logistic regression is less restrictive than linear regression. It does not require normally distributed dependent data or homogeneity of variance.

Predictions made by linear regression are based on the observed changes in the independent data itself. Logistic regression is based on the $\log$ of the odds of a particular event occurring with a given set of observations. Logistic regression's underlying principles are based on probabilities and the nature of the log curve.

Discriminant analysis and logistic regression will produce similar results with dichotomous dependent data except discriminant analysis is more restrictive and complex. Unlike discriminant analysis, logistic regression does not restrict the nature of the independent variable. In contrast with discriminant analysis, logistic regression doesn't restrict categorical independent variables. Discriminant analysis relies on strict adherence to normality and the equal variance assumptions while logistic regression does not have this requirement [7].

Logistic regression has two main uses:

The first is the prediction of group membership. Since logistic regression calculates the probability of success over the probability of failure, the results of the analysis are in the form of an odds ratio.

Logistic regression also provides knowledge of the relationships and strengths among the variables.

There are two primary reasons for choosing the logistic distribution function. First, from a mathematical point of view, it is an extremely flexible and easily used function, and second, it lends itself to a clinically meaningful interpretation [6].

Logistic regressions work with odds and odds ratio. The odds are simply the ratio of the probabilities for the two possible outcomes. If $\pi$ is the probability that the event will occur, then $1-\pi$ is the probability that the event will not occur: 


$$
O d d s=\frac{\pi}{1-\pi}
$$

In the $2 \times 2$ contingency table, within row 1 the odds of success are odds $s_{1}=\pi_{1} /\left(1-\pi_{1}\right)$, and within row 2 the odds of success equal odds $s_{2}=\pi_{2} /\left(1-\pi_{2}\right)$. The ratio of the odds from the two rows,

$$
\theta=\frac{o d d s_{1}}{o d d s_{2}}=\frac{\pi_{1}\left(1-\pi_{2}\right)}{\pi_{2}\left(1-\pi_{1}\right)}
$$

is the odds ratio.

When the response variable is binary, there is considerable empirical evidence that the shape of the response function should be nonlinear. A monotonically increasing or decreasing S-shaped or reverse S-shaped function. For a binary response variable $\mathrm{Y}$ and an explanatory variable $\mathrm{X}$, let $\pi=\mathrm{P}(\mathrm{Y}=1 / \mathrm{X}=\mathrm{x})=1-\mathrm{P}(\mathrm{Y}=0 / \mathrm{X}=\mathrm{x})$. One possible logistic regression model is given by

$$
\pi=\frac{e^{\beta_{0}+\beta_{1} \mathrm{x}}}{1+e^{\beta_{0}+\beta_{1} \mathrm{x}}} \text {, where } \beta_{0}=\text { intercept and } \beta_{1}=\text { slope }
$$

Thus, if the event of interest occurs, in our case tuberculosis, with probability

$$
\begin{gathered}
\pi=\frac{e^{\beta_{0}+\beta_{1} \mathrm{x}}}{1+e^{\beta_{0}+\beta_{1} \mathrm{x}}} \text {, then the odds in favor of success is } \\
\qquad \frac{\pi}{1-\pi}=\frac{e^{\beta_{0}+\beta_{1} \mathrm{x}} / 1+e^{\beta_{0}+\beta_{1} \mathrm{x}}}{1 / 1+e^{\beta_{0}+\beta_{1} \mathrm{x}}}=e^{\beta_{0}+\beta_{1} \mathrm{x}}
\end{gathered}
$$

Taking the natural logarithm of each side of equation

$$
\log i t(\pi)=\ln \left(\frac{\pi}{1-\pi}\right)=\ln \left[e^{\beta_{0}+\beta_{1} \mathrm{x}}\right]=\beta_{0}+\beta_{1} \mathrm{x}
$$

Thus, modeling the probability $\pi$ with logistic function is equivalent to fitting a linear regression model in which the continuous response y has been replaced by the logarithm of the odds of success for a dichotomous random variable. Instead of assuming linear relationship between $\pi$ and x, we assume the linear relationship between $\ln \left(\frac{\pi}{1-\pi}\right)$ and $x$. The technique of fitting a model of this form is known as logistic regression.

Maximum likelihood (ML) estimation is the most common method used to calculate the logit coefficients.

The log likelihood is defined as

$$
L(\beta)=\ln [l(\beta)]=\sum_{i=1}^{n}\left\{y_{i} \ln \left(\pi_{i}\right)+\left(1-y_{i}\right) \ln \left(1-\pi_{i}\right)\right\}
$$

The maximum likelihood estimates are the values of $\beta$ that maximize the above log-likelihood function. Through maximization of the log-likelihood function we can theoretically estimate the vector of parameter $\beta$. But the equation is nonlinear in $\beta$, and as a result the estimates do not have a closed form expression. Therefore, $\beta$ will be obtained by maximizing log- likelihood using iterative algorithm method [8].

Goodness of fit of the model

The goodness of fit or calibration of a model measures how well the model describes the response variable. Assessing goodness of fit involves investigating how the predicted values are closer to the observed values.

The Hosmer-Lemeshow (H-L) test

A better way of assessing the fit of a logistic regression model is comparing the observed and expected numbers of positives for different subgroups of the data. The HosmerLameshow goodness of fit test is useful for assessing overall model fit, particularly when we have many predictor variables, or some of predictor variables are continuous.

The test is similar to a $\chi^{2}$ goodness of fit test and has the advantage of partitioning the observations into groups of approximately equal size, and therefore there are less likely to be groups with very low observed and expected frequencies. The observations are grouped into $\mathrm{g}$ (mostly, $\mathrm{g}=10$ ) based on the predicted probabilities. For either grouping strategy, the Hosmer-Lemeshow goodness-of-fit statistic, $\hat{\mathrm{C}}$, is obtained by calculating the Pearson chi-square statistic from the $g \times 2$ table of observed and estimated expected frequencies. A formula defining the calculation of $\hat{C}$ is as follows:

$$
\hat{C}=\sum_{k=1}^{g} \frac{\left(o_{k}-n_{k}{ }^{\prime} \bar{\pi}_{k}\right)^{2}}{n_{k}{ }^{\prime} \bar{\pi}_{k}\left(1-\bar{\pi}_{k}\right)} \sim \chi_{(g-2)}^{2}
$$

where, $g$ denotes the number of groups, $n_{k}^{\prime}$ is the total number of observations in the $\mathrm{k}^{\text {th }}$ group, $c_{k}$ denotes the number of covariate patterns in the $\mathrm{k}^{\text {th }}$ decile, $o_{k}$ is the number of responses among the $c_{k}$ covariate patterns, and $\bar{\pi}$ is the average estimated probability. The distribution of the statistic $\hat{\mathrm{C}}$ is well approximated by the chi-square distribution with $g$ - 2 degrees of freedom, $\chi_{(g-2)}^{2}[6]$.

If $\mathrm{p}$-value for the Hosmer-Lemeshow goodness-of-fit test is greater than 0.05 , we will not reject the null hypothesis that there is no difference between observed and model predicted values, implying that the model estimates are adequate to fit the data at an acceptable level or if the observed and expected numbers are sufficiently close, then we can assume that we have an adequate model.

\section{Results and Discussion}

\subsection{Results}

Information on the occupational status of women obtained from a total of 23,666 women in Ethiopia was studied. Based on table 1, 5,015 (21.2\%) women was unemployed. Conversely, $78.8 \%$ of the women was employed in Ethiopia.

Table 1. Percentage of occupational status.

\begin{tabular}{llll}
\hline & & Number & percent \\
\hline Occupational & unemployed & 5,015 & $21.2 \%$ \\
status & employed & 18,651 & $78.8 \%$ \\
\hline
\end{tabular}

From table 2 show that $8.9 \%$ and $12.3 \%$ of urban and rural women were unemployed in the 12 months before the survey, 
respectively. The percent of unemployment women of currently pregnant and not pregnant were $72.9 \%$ and $19.3 \%$, respectively. Similarly, the percent of unemployment women for age of households from less than 20, 20-40 and above 40 were $0.1 \%, 8.6 \%$ and $12.4 \%$, respectively. In addition, $4.2 \%$ and $17 \%$ of unmarried and married women were unemployment, respectively. Moreover, the percent of unemployment women for currently breastfeeding, not currently breastfeeding, no educated, primary, secondary, higher, poor, middle and rich were $6.8 \%, 14.4 \%, 15.1 \%$, $2.2 \%, 3.5 \%, 0.4 \%, 8.4 \%, 4.4 \%$ and $8.4 \%$, respectively.

$15.7 \%, 5.5 \%$ and $0.004 \%$ of age of women at first birth from less than 20, 20-40 and more than 40 were unemployed, respectively.

Table 2. Frequency of the variables.

\begin{tabular}{llll}
\hline \multirow{2}{*}{ Variable } & category & Occupational status & yes \\
\cline { 3 - 4 } Types of place of residence & urban & $2098(8.9)$ & $5388(22.8 \%)$ \\
& rural & $2917(12.3 \%)$ & $13263(56 \%)$ \\
Currently pregnant & no & $4575(19.3 \%)$ & $440(1.9 \%)$ \\
& yes & $17247(72.9 \%)$ & $1404(5.9 \%)$ \\
Age of households & Less than 20 & $33(0.1 \%)$ & $120(0.5 \%)$ \\
& $20-40$ & $2042(8.6 \%)$ & $7253(30.6 \%)$ \\
Currently marital status & More than 40 & $2940(12.4 \%)$ & $11278(47.7 \%)$ \\
& unmarried & $989(4.2 \%)$ & $2485(10.5 \%)$ \\
Currently breastfeeding & married & $4026(17 \%)$ & $16166(68.3 \%)$ \\
& no & $3408(14.4 \%)$ & $13284(56.1 \%)$ \\
Age of respondent at the first birth & $1607(6.8 \%)$ & $5367(22.7 \%)$ \\
& yes & $3705(15.7 \%)$ & $14235(60.1 \%)$ \\
& Less than 20 & $1309(5.5 \%)$ & $4415(18.7 \%)$ \\
Highest education level & $20-40$ & $1(0.004 \%)$ & $1(0.004 \%)$ \\
& More than 40 & $3573(15.1 \%)$ & $14629(61.8 \%)$ \\
& No education & $526(2.2 \%)$ & $2084(8.8 \%)$ \\
Wealth index & primary & $819(3.5 \%)$ & $1663(7 \%)$ \\
& secondary & $97(0.4 \%)$ & $275(1.2 \%)$ \\
& higher & $1978(8.4 \%)$ & $9210(38.9 \%)$ \\
& poor & $1049(4.4 \%)$ & $4190(17.7 \%)$ \\
& middle & $1988(8.4 \%)$ & $5251(22.2 \%)$ \\
\hline
\end{tabular}

Table 3 shows that the $p$-value $=0.051>0.05$ at $5 \%$ level of significance, we don't reject the null hypothesis of no difference between observed and model predicted values and conclude that the model is adequate

Table 3. Hosmer and Lemeshow Test.

\begin{tabular}{llll}
\hline Step & Chi-square & df & Sig. \\
\hline 1 & 15.43 & 8 & 0.051 \\
\hline
\end{tabular}

Table 4. Binary logistic regression analysis for factors found to be associated with unemployment women in Ethiopia.

\begin{tabular}{|c|c|c|c|c|c|c|}
\hline Occupational status & Odds Ratio & Std. Err. & $\mathbf{z}$ & $\mathbf{P}>\mathbf{Z}$ & [95\% Conf. & Interval] \\
\hline \multicolumn{7}{|l|}{ Place of residence } \\
\hline Rural & 0.70554 & 0.029337 & -8.39 & 0.000 & 0.650322 & 0.765447 \\
\hline \multicolumn{7}{|l|}{ Highest education level } \\
\hline Primary & 0.925744 & 0.049246 & -1.45 & 0.147 & 0.834084 & 1.027476 \\
\hline Secondary & 1.509644 & 0.075722 & 8.21 & 0.000 & 1.368293 & 1.665597 \\
\hline Higher & 0.983328 & 0.121377 & -0.14 & 0.892 & 0.772024 & 1.252466 \\
\hline \multicolumn{7}{|l|}{ Currently pregnant } \\
\hline \multicolumn{7}{|l|}{ Currently breastfeeding } \\
\hline Yes & 1.334616 & 0.048473 & 7.95 & 0.000 & 1.242913 & 1.433084 \\
\hline \multicolumn{7}{|l|}{ Age of households } \\
\hline $20-40$ & 1.06595 & 0.214393 & 0.32 & 0.751 & 0.71868 & 1.581021 \\
\hline above 40 & 1.005348 & 0.201816 & 0.03 & 0.979 & 0.678335 & 1.490009 \\
\hline \multicolumn{7}{|l|}{ Wealth index } \\
\hline middle & 1.098474 & 0.047789 & 2.16 & 0.031 & 1.008691 & 1.196249 \\
\hline $20-40$ & 1.177109 & 0.043767 & 4.39 & 0.000 & 1.094378 & 1.266094 \\
\hline above 40 & 3.287822 & 4.728374 & 0.83 & 0.408 & 0.196225 & 55.08864 \\
\hline \multicolumn{7}{|l|}{ Currently marital status } \\
\hline married & 0.684879 & 0.029697 & -8.73 & 0.000 & 0.629077 & 0.745629 \\
\hline cons & 0.326726 & 0.0677 & -5.4 & 0 & 0.217676 & 0.490409 \\
\hline
\end{tabular}


Table 4 shows the effect of explanatory variables on dependent variable. When we look at place of residence, the odds of unemployment of women for living in rural was 0.7 times lower than urban area. Similarly, Women whose pregnant status for currently pregnant were 1.4 times more likely to be unemployed than those women had not currently pregnant while women who were currently breastfeeding a child were 1.3 times more likely to be unemployed than those women who were not currently breastfeeding.

Women whose educational level was secondary were 1.5 times more likely to be unemployed than those women had no education. In addition, Married women were 0.7 times less likely to be unemployed than unmarried women.

The odds of unemployment of women for age of respondent at the first birth from 20-40 were 1.2 times higher than the odds of unemployment of women whose age less than 20, controlling other variables in the model. Moreover, the odds of unemployment women for rich and medium households were 1.1 and 1.3 times more likely to poor households, respectively.

\subsection{Discussion}

A Binary Logistic Regression Analysis is used to identify the most important determinant factors which are associated with the occupational status of women in Ethiopia. Women whose educational level was secondary were more likely to be unemployed than those women had no education. This finding is contrary by the previous researchers $[9,10]$. This study also showed that pregnant women were more likely to be unemployed than not pregnant women. Women who were pregnant in a given year had a lower probability of participating in the labor market than women who had not been pregnant [1]. For the education level, the result reveals that the education level of secondary school were more likely to be unemployed than those women had no education, consistent with [12]. The present study also showed that Unmarried women were less likely to work than are married women, consistent with [13, 14].

According to this findings, as compared with women residing in higher economic status households were more likely to be unemployed than for poor households. This finding is inconsistent with other studies [9] showing that women of very poor or poor (low economic status) households have the highest rates of unemployment. In addition, women who were currently breastfeeding a child were more likely to be unemployed than those women who were not currently breastfeeding. This result is confirmed by the previous researches [15]. Moreover, the odds of unemployment of women for age of respondent at the first birth from 20-40 were higher than the odds of unemployment of women whose age less than 20, controlling other variables in the model. This is consistent with [16].

\section{Conclusion and Recommendation}

\subsection{Conclusion}

In this study the determinants of unemployment in Ethiopia and its impact on household welfare is investigated using data from the EDHS 2016. The main objective of this study was to identify determinants of women unemployment in Ethiopia. The study revealed the effect of demographic and socio-economic determinants on women unemployment. The result of binary logistic regression model also revealed that place of residence, educational level of woman, currently pregnant, currently breastfeeding, wealth index, age of the respondent at the first birth and marital status had significant effect on women unemployment at $5 \%$ level of significance.

\subsection{Recommendation}

Based on the findings of this study the following recommendations are made:

The age of women at the first birth significantly determines the women unemployment. Age of women at first birth (less than 20 years) are less affected by unemployment as compared to youths (20-40). Hence, the government should give special attention to youngsters by providing them different job opportunities. Women with highest economic status of households are more likely unemployed than women with poor households. Highest economic status through family planning can increase burden of women to their family and in turn decreases women's labor market participation. Hence, the concerned bodies should provide women family planning program. Currently pregnant and currently breastfeeding women are more likely unemployed than unmarried women. They are busy in home activities like taking care of their children, preparing food, washing clothes etc. Hence, their husbands should share burden of them and motivate them to participate in labor market and generate income. Since women with higher level of education (secondary) and unmarried women are more likely unemployed than women with lower level of education and married women, respectively. Policies and strategies that create more job opportunities should be implemented.

\section{Abbreviations}

EDHS: Ethiopia Demographic and Health Survey

CSA: Central Statistical Agency

USAID: United States Agency for International Development

UNFPA: United Nations Population Fund

UNICEF: United Nations Children's Fund

UN: United Nation

ICF: International child fund

HIV: Human Immunodeficiency Virus

AIDS: Acquired Immunodeficiency Syndrome

SNNPR: Southern Nations, Nationalities, and People's Region 


\section{References}

[1] Rafiq M, Ahmad I, Ullah A, Khan Z. Determinants of unemployment: A case study of Pakistan economy (19982008). Abasyn journal of social sciences. 2010; 3 (1): 17-24.

[2] Eita JH, Ashipala JM. Determinants of unemployment in Namibia. International Journal of Business and Management. 2010 Oct 1; 5 (10): 92.

[3] Haile GA. The incidence of youth unemployment in urban Ethiopia. In 2nd EAF International Symposium on Contemporary Development Issues in Ethiopia 2003.

[4] Chen MA, Vanek J, Carr M. Mainstreaming informal employment and gender in poverty reduction: A handbook for policy-makers and other stakeholders. Commonwealth secretariat; 2004.

[5] World Bank. World development report 2012: Gender equality and development. World Bank Publications; 2011.

[6] Hosmer DW, Lemeshow S, Sturdivant RX. Introduction to the logistic regression model. Applied logistic regression. 2000; 2 : $1-30$.

[7] Healy LM. Logistic regression: An overview. Eastern Michighan College of Technology. 2006 Mar 20.

[8] Agresti, A. (2002). An Introduction to Categorical data Analysis. $2^{\text {nd }}$ Edition, John Wiley and Sons. Inc., New York.

[9] Bhorat H. Unemployment in South Africa: Descriptors and determinants, unpub\# lished consultant report for OECD.

[10] Gizachew Gobebo, Wondaferahu Mulugeta and Temesgen Yaekob. Determinants of women unemployment: evidence from ethiopia (case of halabatown, SNNPR), 2017.

[11] Winter C. Female earnings, labor force participation and discrimination in Venezuela, 1989. Case Studies V 2 on Women's Employment and Pay in Latin America. 1992: 463.

[12] Kassa AF. Unemployment in Urban Ethiopia: Determinants and Impact on household welfare. Ethiopian Journal of Economics. 2012; 21 (2): 127-57.

[13] Krishnan P. Family background, education and employment in urban Ethiopia. Oxford Bulletin of Economics and Statistics. 1996 Feb; 58 (1): 167-83.

[14] Abebe Fikre K. Unemployment in Urban Ethiopia.

[15] Chekol DA, Biks GA, Gelaw YA, Melsew YA. Exclusive breastfeeding and mothers' employment status in Gondar town, Northwest Ethiopia: a comparative cross-sectional study. International breastfeeding journal. 2017 Dec; 12 (1): 27.

[16] Demographic E. Health Survey Central Statistical Agency Addis Ababa. Ethiopia ICF International Calverton, Maryland, USA. 2011: 180-6. 